\title{
Propagation of Failure in Adhesive Joints between CFRPIGFRP Beams Subjected to Cyclic Bending
}

\author{
Yuliia Terebus ${ }^{\mathrm{a}}$, Dominik Głowacki ${ }^{\mathrm{b}}$, Mirosław Rodzewicz ${ }^{\mathrm{c}}$ \\ Warsaw University of Technology, Institute of Aeronautics and Applied Mechanics, \\ Nowowiejska 24 00-665 Warsaw, Poland \\ ayuliia.terebus@gmail.com, bdglowacki@meil.pw.edu.pl, cmiro@meil.pw.edu.pl
}

\section{Keywords: Composite Material, Adhesive Joint, Fatigue Test}

\begin{abstract}
Last decades were crucial for composite structures. They were highly developed and started to be widely used in aircraft industry. This allowed engineers to overcome a set of issues connected with incapability of known materials to support modern requirements and needs. Merging together two or more materials in special way enabled to save advantages of each and get rid of individual drawbacks. As a result such a "hybrid" material got improved structural properties. However, in the aircraft industry important are not only individual parameters of the material, but how it can be joined with other part. Mechanical fasteners and adhesives types of joining are used with composites materials depending on application and material composition. Even as both types are still used, adhesive bonding of composite material are more beneficial in comparison with traditional mechanical fasteners. The aim of this article is to perform fatigue test of adhesive joints between CFRP and GFRP composites and analyze obtained results. In order to do that, destructive loads levels were investigated with mathematical model and with FEM simulation in ANSYS software.
\end{abstract}

\section{Introduction}

Reliability and safety play a primary role in the functioning and development of aviation. Since the beginning of aviation progress the reliability of the aircraft structure has been very important. That is why improving the quality, reliability and durability of structural elements have a special place in research investigation.

Nevertheless, the greatest interest have composite materials which are widely used in the aircraft industry and today can be found in many different kinds of airplanes, as well as gliders. Aircraft structures are commonly made up of 50 to 70 percent composite material. Moreover, it is hard to predict and detect the material fracture. So, reliability of composite structures plays an important role in aviation industry [1]. Very often a critical element regarding reliability is a joint between structural elements. The paper concerns investigations into adhesive joint (glueconnection) between CFRP and GFRP flat shells. Several methods are in use for testing such a joints [2, 3], but for the purpose of the research presented in this paper there were elaborated a special method. The uniqueness of this method lies on generating the state of shear stresses in adhesive joint between two composite shells glued together, by subjecting them into bending with constant value radius curvature. There were applied the specimen in the form of rectangular beams consisted of two halves: CFRP and GFRP orthogonal laminates, which were glued together only in a certain parts of their surface. In that way there were obtained the conditions of "notched" connection, which facilities the debonding between both halves, and effectively increases it's grow (especially in a low-cycle fatigue mode).

This aspect was very important for the authors, because this research was considered by them as a "pre-check" of a new testing method, so the results and answer regarding applicability of this method should be delivered in a short time. It is also worth to mention that the same 
specimens were used in another research (i.e. detection of debonding zone using ultrasonic flow detector), which is not described in this paper. That is why there were applied the specimens consisted of transparent and non-transparent composites, as the progress of debonding can be easily observed from "transparent side" of the specimen (and be measured using the caliper), so the results of those observations can be used for verification of ultrasonic inspection results, which were obtained from "non-transparent side”. Nevertheless CFRP/GFRP structures appear to be used in practice, (e.g. in AOS-71 glider structure [4]).

\section{Specimen Preparation}

Composite specimens were manufactured at Warsaw University of Technology. They were cut from CFRP/GFRP workpiece (i.e. composite plate made from carbon and glass fabrics, and epoxy resin). Materials used for the workpiece fabrication were: Interglas 92125 (280 g/m² glass fabric), ECC 452 (204 g/m² carbon fabric), Epidian 53/Z1 (resin/hardener mixed proportion: 100:10.5, volume fracture: 0.5 ). A following layout was applied: 5 layers of carbon fabric consequently and then 5 layers of glass fabric; in each layer the reinforcement fibers were oriented alongside the plate edges.

The plate had an inclusion in the middle of its thickness (i.e. between CFRP and GFRP composite) made from $0.02 \mathrm{~mm}$ polyester foil (see Fig. 1). The role of this foil was to shape the dimensions of adhesive joint between CFRP and GFRP halves of the specimen and to simulate initial failure of this connection. Therefore, the foil was shaped as it is shown on the schematic sketch in Fig. 1.

Manufacturing Procedure:

1. Two flat pieces of laminated wooden board were prepared as molds.

2. The carbon fabric and glass fabric pieces of necessary dimensions were cut out from the roll. The piece of polyester foil with cutouts was prepared.

3. Molds and polyester foil were coated

with wax to provide easy separation of the workpiece from mold.

4. The sheets of reinforcement fabrics were consequently put on the mold and impregnated by Epidian 53/Z1 resin mixture (at first 5 carbon, then the separation foil, and then 5 glass). The composite plate was hand-

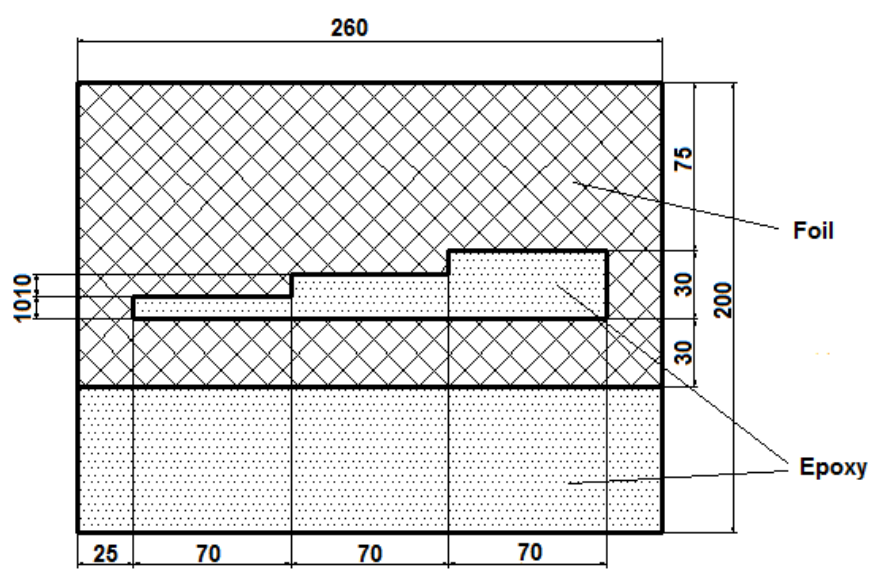

Fig. 1. Schematic sketch of the middle-plane cross-section of composite workpiece

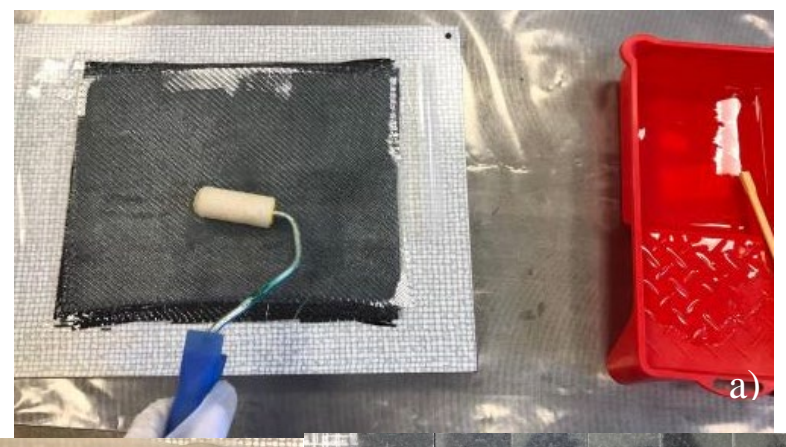
rolled after impregnation of each layer to remove air

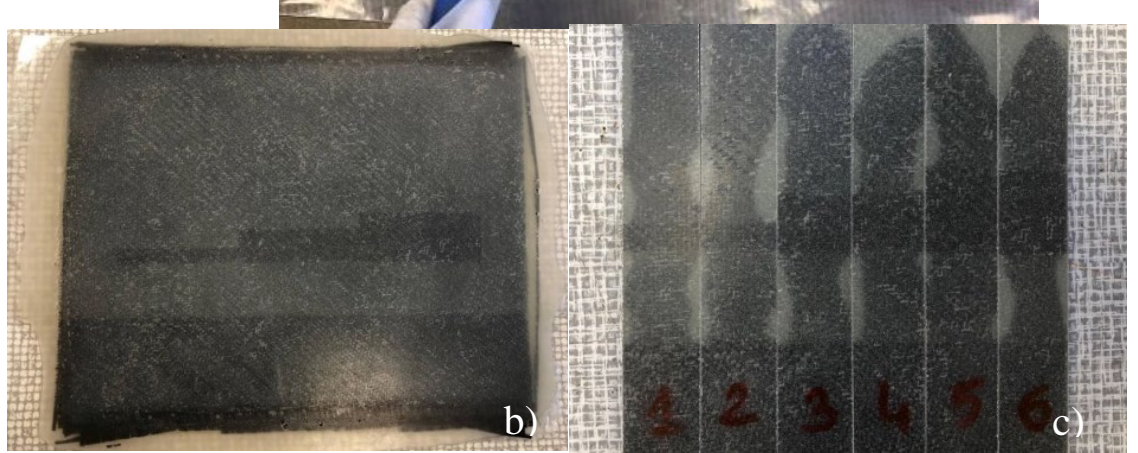

Fig. 2. Specimen manufacturing:

a) layers impregnation with epoxy;

b) workpiece; c) specimens 
bubbles and provide uniform distribution of epoxy (Fig. 2a).

5. Second mold plate was put on the top of composite plate and pressed (about $100 \mathrm{kPa}$ ) during first step of 2-stages curing process (16 hours at room temperature and then 8 hours at temperature of $60^{\circ} \mathrm{C}$ ).

6. Finally the composite workpiece (see Fig. 2b) was cut into 6 rectangular specimens $150 \mathrm{~mm} \times 25 \mathrm{~mm}$ (i.e. two specimens for each length of adhesive joints between CFRP and GFRP halves). As a result were obtained 3 pairs of specimens having 10, 20, and $30 \mathrm{~mm}$ adhesive joints to be subjected into fatigue tests (Fig. 2c).

\section{Fatigue Test}

Fatigue tests were performed in laboratory of the Faculty of Power and Aeronautical Engineering of Warsaw University of Technology.

There was used pneumatic actuator powered by pressure system consisting of long pneumatic piston-pomp and a screw-servomotor linked with the piston of this pomp (see Fig. 3). The servomotor was controlled by computer using input file with programed load/deflection sequence (i.e. sequence of pomp piston movement).

The base of the specimen was fixed in a special holder (assuring the limitation of specimen deflection under load), while the tip of specimens was subjected by the actuator to transversal movement (low-frequency oscillations). The holder consisted of two wooden blocks having radius of contact-surface $150 \mathrm{~mm}$. In consequence the specimen was bended and the curvature of deflection was limited by the radius of those blocks (see Fig. 4).

The number of bending cycles applied was captured by electronic counter.

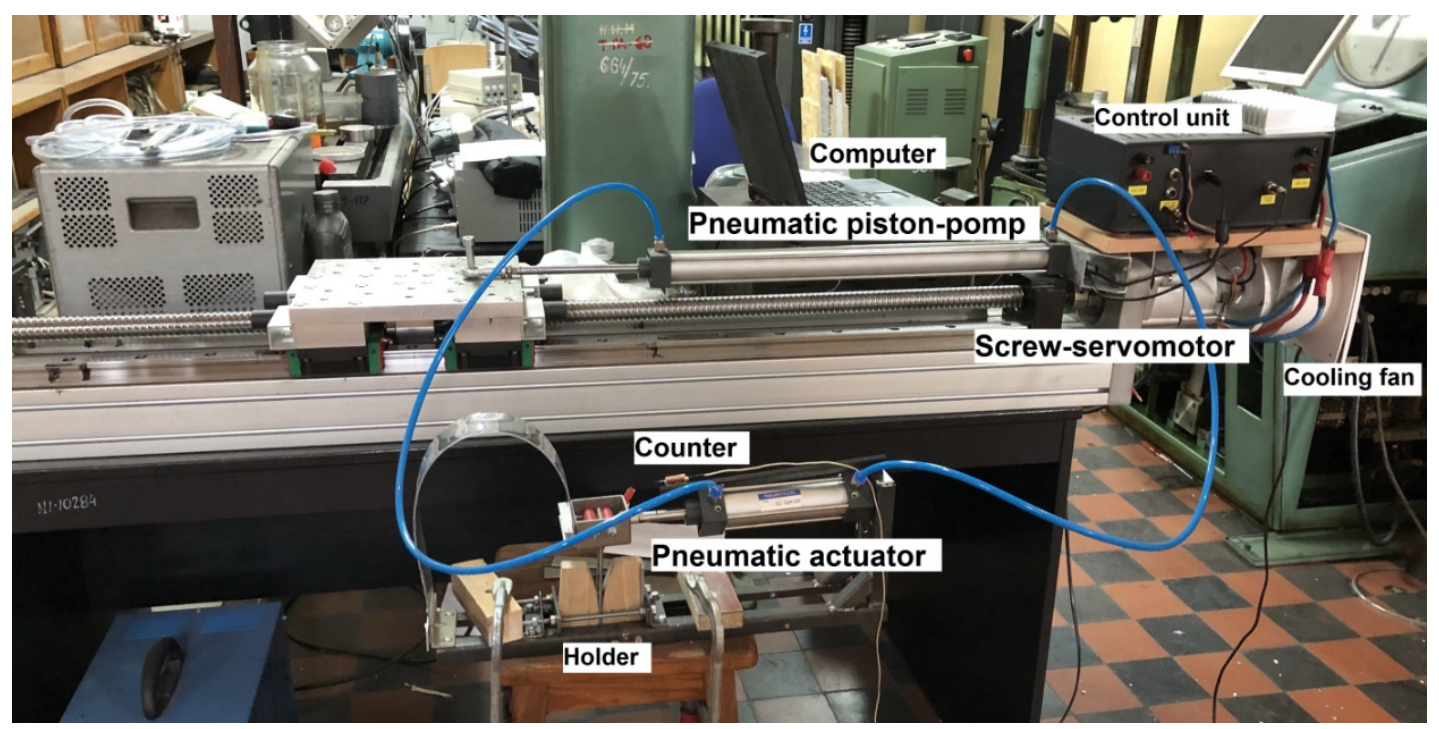

Fig. 3. Fatigue test stand

Performed experiment was a low-cycle fatigue test. The load cycles applied during tests were of the same amplitude and frequency.

Testing Procedure. Each specimen was attached to fatigue stand and subjected into cyclic bending. After each 100 bending cycles the distance of failure propagation in adhesive joint between CFRP and GFRP halves of specimen was measured using caliper, which was made possible by transparence of the GFRP part of the specimen (see Fig.5). 


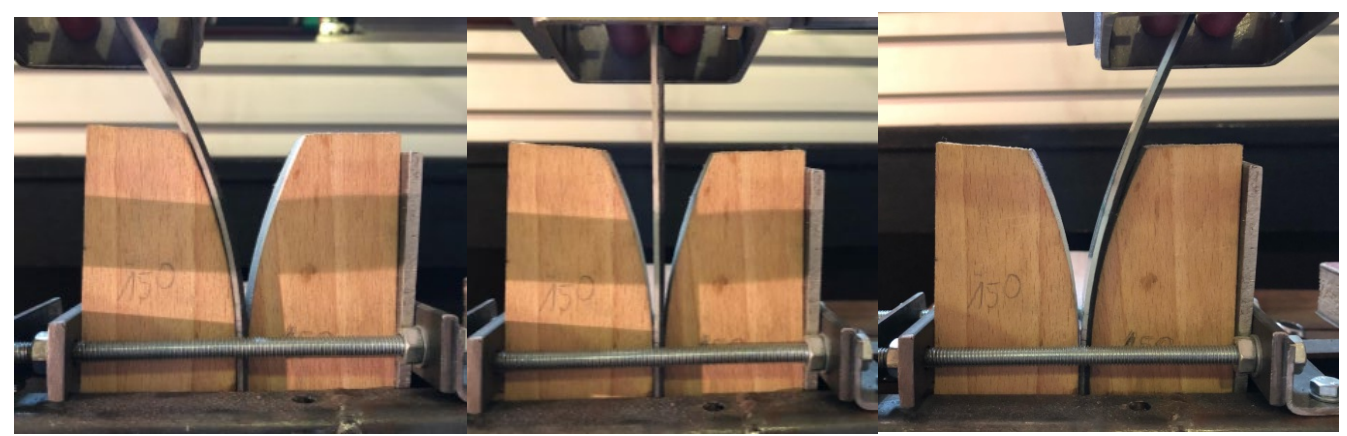

Fig. 4. Deflection position of specimens

The view of specimens after first 100 and 400 bending cycles is shown in Fig. 5.
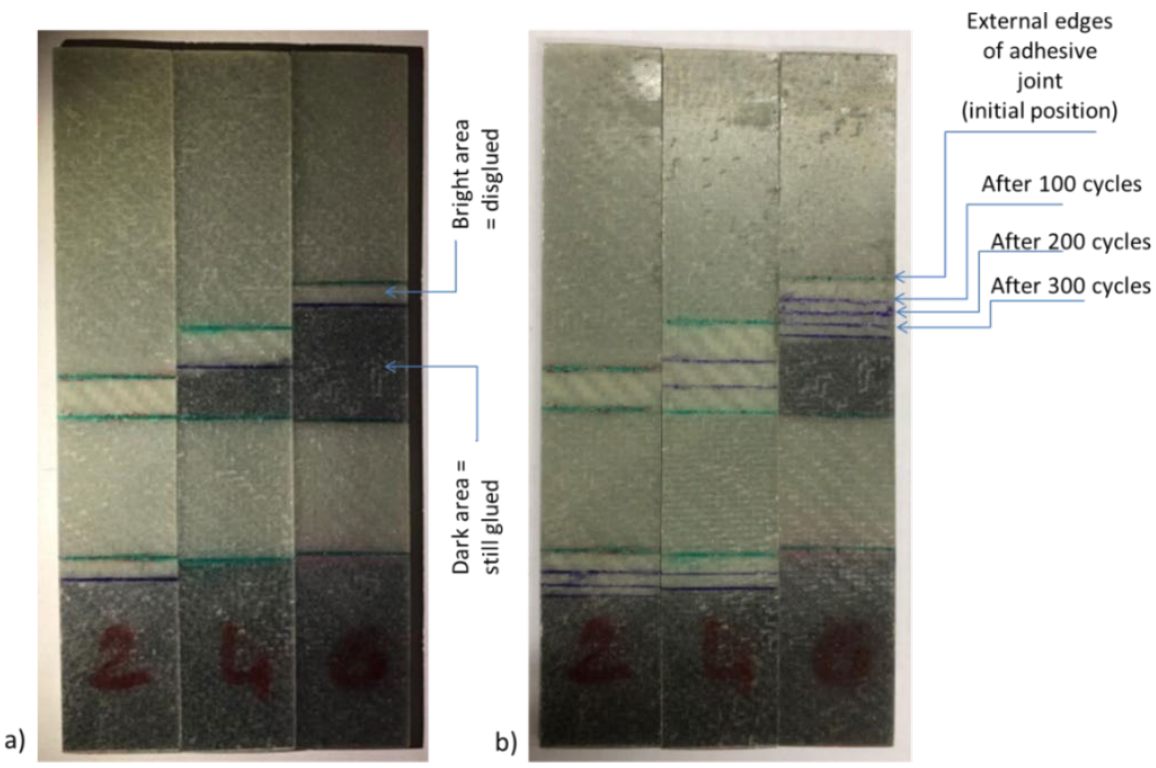

Fig.5 Specimens after 100 (a) and 400 (b) bending cycles

After finishing the set of experiments the following results were acquired:

- The specimen \#2 (adhesive joint length $10 \mathrm{~mm}$ ) has broked in 20 cycles;

- The specimen \#4 (adhesive joint length $20 \mathrm{~mm}$ ) has broked in 217 cycles;

- The specimen \#6 (adhesive joint length $30 \mathrm{~mm}$ ) has broked in 763 cycles.

They are collected in Tab. 1 and illustrated in Fig. 6.

Table 1. Fatigue test results

\begin{tabular}{|c|c|c|}
\cline { 2 - 3 } \multicolumn{1}{c|}{} & Number of cycles & Failure propagation, [mm] \\
\hline \multirow{3}{*}{ Specimen 2} & 0 & 0 \\
\cline { 2 - 3 } & 20 & 10 \\
\hline \multirow{4}{*}{ Specimen 4 } & 0 & 0 \\
\cline { 2 - 3 } & 100 & 8.5 \\
\cline { 2 - 3 } & 200 & 14 \\
\hline \multirow{5}{*}{ Specimen 6 } & 217 & 20 \\
\cline { 2 - 3 } & 0 & 0 \\
\cline { 2 - 3 } & 100 & 5 \\
\cline { 2 - 3 } & 200 & 8 \\
\cline { 2 - 3 } & 300 & 10.5 \\
\cline { 2 - 3 } & 400 & 13 \\
\cline { 2 - 3 } & 500 & 15.5 \\
\cline { 2 - 3 } & 600 & 18 \\
\hline
\end{tabular}




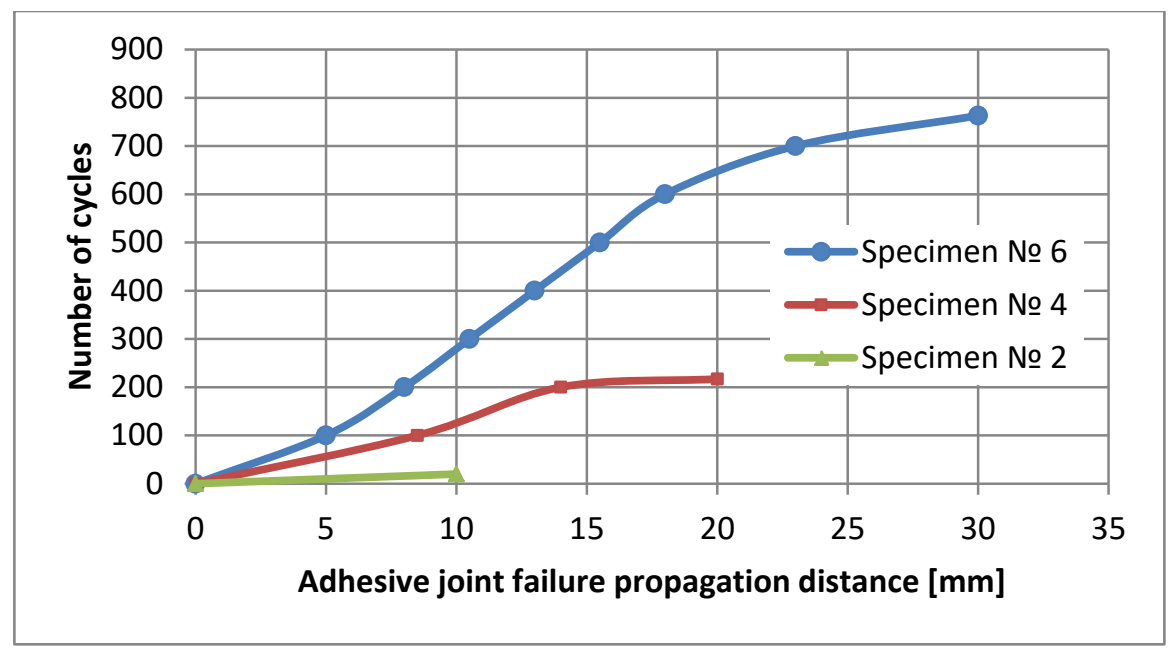

Fig. 6. Number of cycles to failure

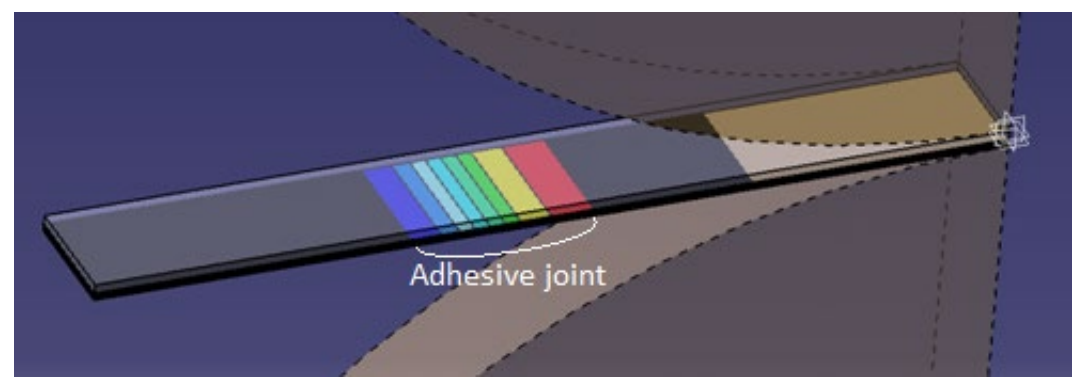

Fig. 7. Visualization of adhesive joint failure propagation

As it can be seen from the graph firstly failure propagates linearly up to last $10 \mathrm{~mm}$. Only a few load cycles are needed to destroy last $10 \mathrm{~mm}$. However, in specimen with adhesive joint lenght $30 \mathrm{~mm}$ the first 200 cycles led to higher failure propagation compared with next 500 cycles. It can be explained by high shear stress at the tips of adhesive joint in comparison to the stress in the middle part of this joint.

\section{Estimation of Destructive Loads Level with Mathematical Model}

Due to specimen cyclic bending the CFRP and GFRP parts of the specimen are compressed or stretched (depending on the direction of actuator movement). As a result the adhesive join between CFRP and GFRP halves of the specimen is subjected to cyclic shear deformation.

The load level in adhesive joint was estimated based on the simplified model, which is shown in Fig. 8. The thickness of adhesive layer was neglected here. At the beginning there were considered two theoretically possible situations: case "fully integrated", and case "without adhesion". For the first case the specimen

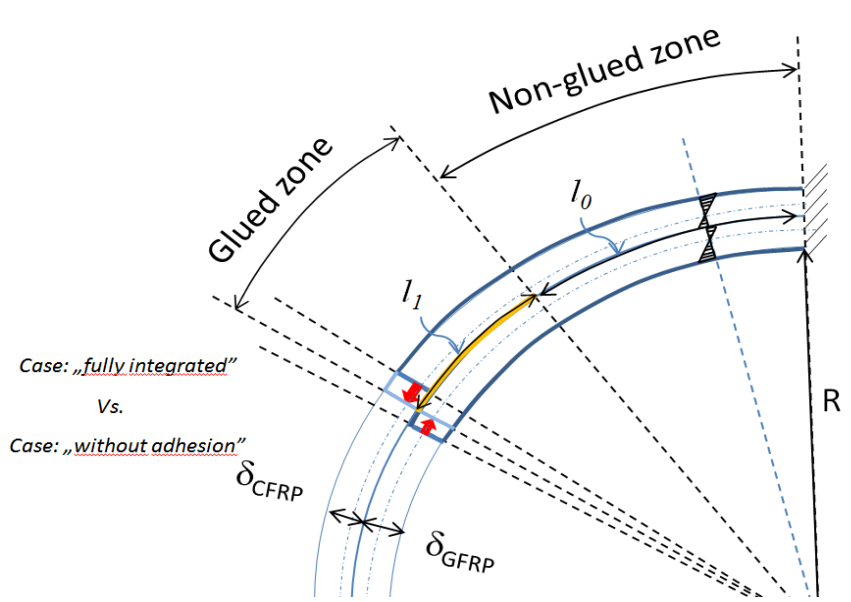

Fig. 8. Simplified model of the specimen for shear stress estimation in contact zone has one neutral plane (i.e. plane with elongation equal zero), which is placed in the middle of specimen thickness near the contact 
zone of GFRP and CFRP halves (depending on the ratio of their bending stiffness). For the second case the GFRP and CFRP specimen-halves work separately as two bended beams. Each beam has neutral plane placed in the mid-point of its thickness. For a real case, one can expect the intermediate situation: i.e. the neutral planes of both bended halves have to be placed somewhere between the mid-point and contact zone. Due to different curvature of both bended beams the length of outer plane of GFRP beam becomes longer than the length of inner plane of CFRP beam. In order to calculate the elongations there was used the formula (1) concerning pure bending [5]:

$$
\varepsilon=-\frac{z}{\rho}
$$

where $\mathrm{z}$ - is a distance from the mid-plane to the plane considered, and $\rho$ - is a radius of midplane curvature.

The relative elongations of outer plane of GFRP and inner plane of CFRP were calculated according formulas (2) and (3). The $k$-factor here is the ratio positioning neutral planes of bended beams between their inner and outer faces; ( $k=0,5$ for the case "without adhesion”).

In case when the specimen is deformed as it is shown in Fig.8, the strain of GFRP and CFRP can be calculated from equations (2) and (3) correspondingly:

$$
\varepsilon_{G F R P}=\frac{k * \delta_{G F R P}}{R+\delta_{G F R P}} \text { and } \varepsilon_{C F R P}=\frac{-(1-k) * \delta_{C F R P}}{R+\delta_{G F R P}+(1-k) * \delta_{C F R P}}
$$

Having values of those elongations and neglecting shear deformation of the glue,

it is possible to calculate axial forces necessary to compensate those elongations (see red arrows in Fig. 8) using formulas (3) and (4), which are related to unitary width of the specimen.

$$
F_{G F R P}=\varepsilon_{G F R P} * E_{G F R P} * \delta_{G F R P} * 1 ; \text { and } F_{C F R P}=\varepsilon_{C F R P} * E_{C F R P} * \delta_{C F R P} * 1 ;
$$

Both forces should be equal for pure bending, and this fact depends on $k$-factor value.

In case of input-data used for considered model (i.e.: $l_{0}=30 \mathrm{~mm}, l_{1}=10$ or 20 or $30 \mathrm{~mm}, E_{G F R P}$ $\left.=20000 \mathrm{MPa}, E_{C F R P}=55000 \mathrm{MPa}, R=150 \mathrm{~mm}, \delta_{C F R P}=1,55 \mathrm{~mm}, \delta_{C F R P}=1,2 \mathrm{~mm}\right)-$ the balance was obtained for $k$-value equal 0,67629 .

Assuming that in case of adhesive connection the same forces are produced by a shear stress in a glued zone, it was possible to estimate mean value of shear stress for each length of glue connection $l_{1}$ :

$$
\tau_{\text {mean }}=\frac{P_{G F R P}}{l_{1} * 1}
$$

The results of such estimations are stored in Table 2. It should be pointed, that maximum values of shear stresses in adhesive joint-ends may be higher because of hyperbolic-nature of shear-stress distribution function along adhesive joint [6].

Table 2. Shear stress estimation

\begin{tabular}{|c|c|c|c|}
\hline Length of glue zone $l_{1}$ & 10 & 20 & 30 \\
\hline Shear stress [MPa] & 13,8 & 6,9 & 4,6 \\
\hline
\end{tabular}


As the shear stress limit for epoxy resin is about $30 \mathrm{MPa}$, it means that the loads in adhesive joint are relatively high and consistent with high-cycle fatigue testing idea.

\section{Calculation of Destructive Loads Level with FEM Simulation}

The next step of investigation into shear stress values at adhesive joint was implementation of finite element method (FEM) using ANSYS software system [7]. There was applied simplified 2D model (see Fig. 9). consisted from 2091 finite elements and 14761 nodes.

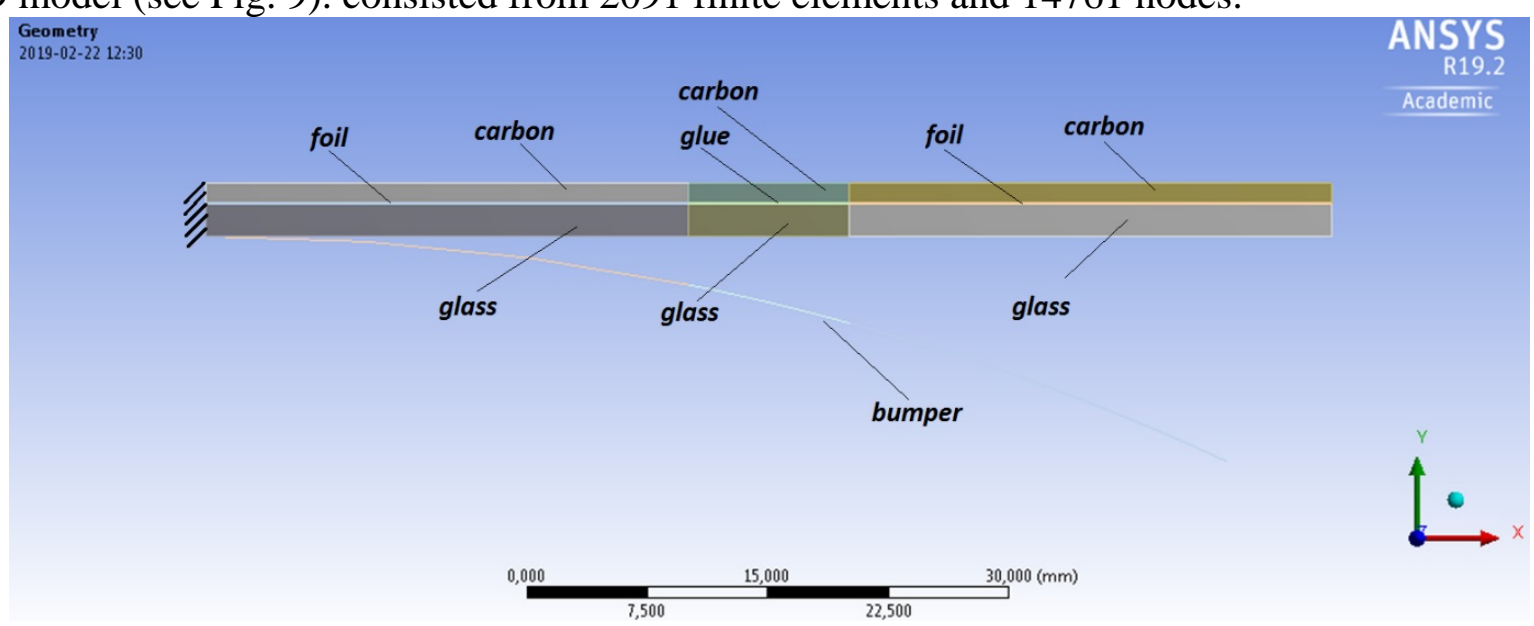

Fig.9. Structure of numerical model of the specimen

Geometry parameters of the specimen were the same like in previous chapter. There also were considered 3 different lengths of adhesive joint: 10, 20 and $30 \mathrm{~mm}$. For all those cases the thickness of glue layer was the equal $0,1 \mathrm{~mm}$. The places between specimen halves, which were outside the join were separated by the foil of the same thickness, but having very low E- and Gmodulus in comparison with the material of adhesive joint.

For simplicity there was assumed that all specimen components were built from isotropic materials. Their parameters are specified in Table 3.

Table 3. Material parameters of FEM model

\begin{tabular}{|l|l|l|l|l|}
\cline { 2 - 5 } \multicolumn{1}{c|}{} & $\begin{array}{l}\text { Young's } \\
\text { Modulus, [MPa] }\end{array}$ & Poisson's Ratio & $\begin{array}{l}\text { Bulk Modulus, } \\
{[\mathrm{MPa}]}\end{array}$ & $\begin{array}{l}\text { Shear Modulus, } \\
{[\mathrm{MPa}]}\end{array}$ \\
\hline CFRP & 54000 & 0.3 & 45000 & 20769 \\
\hline GFRP & 20000 & 0.3 & 16667 & 7692.3 \\
\hline Distance foil & 10 & 0.3 & 8.3333 & 3.8462 \\
\hline $\begin{array}{l}\text { Adhesive joint } \\
\text { (epoxy glue) }\end{array}$ & 3000 & 0.3 & 2500 & 1153.8 \\
\hline
\end{tabular}

The specimen-model was fixed at left end (see Fig. 9). On the opposite end, instead of load there was introduced the displacement along local Y-axis, which caused almost full contact of the specimen with model of "bumper" having curvature $\mathrm{R}=150 \mathrm{~mm}$. In order to avoid mutual penetration there were applied contact elements between the "bumper" and the specimen, which did not allowed deflection under "bumper" surface.

The results of calculations are presented below in the form of bitmaps.

The first one is a map of total deformation (Fig.10). 


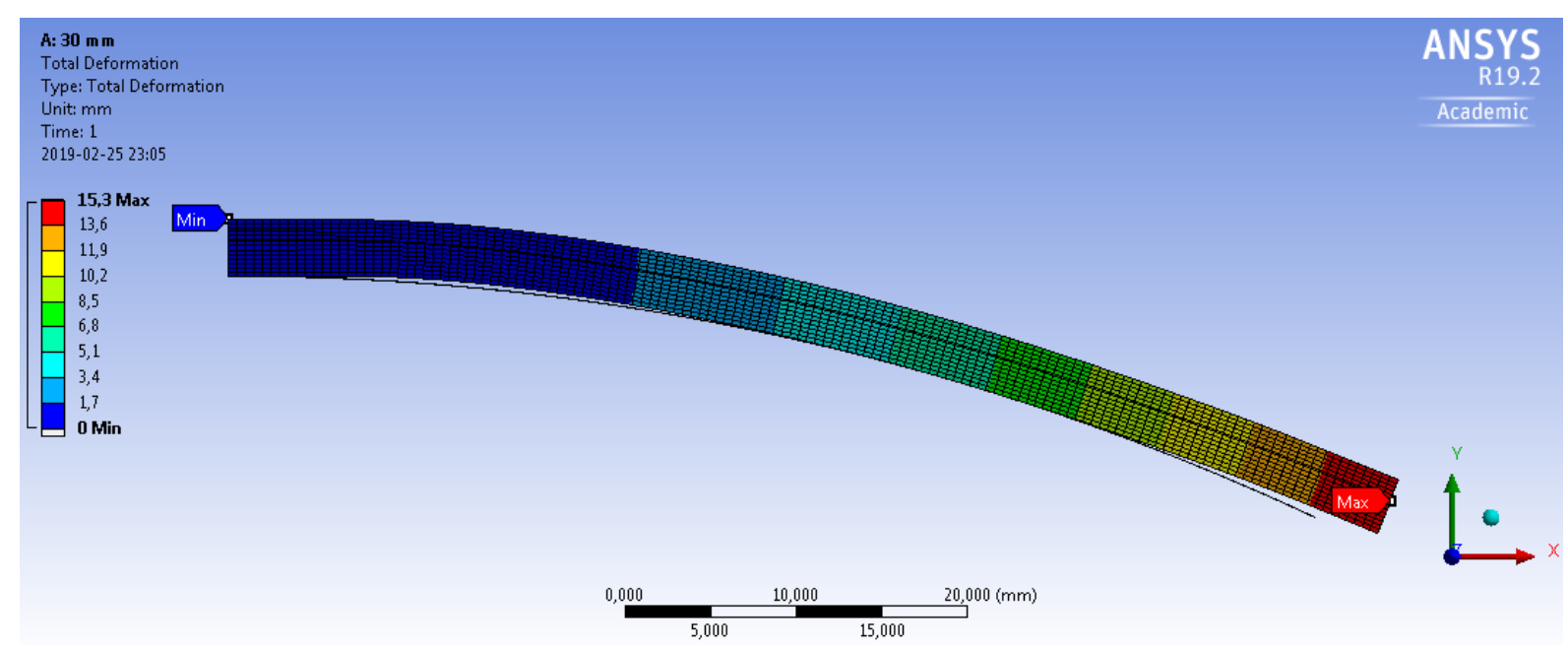

Fig. 10. Map of total deformation

As it arises from Fig. 10, the specimen does not touch the bumper along whole length, but good contact is visible in the middle part of the specimen, especially at the zone containing adhesive connection. The influence on such behavior has higher bending stiffness of the specimen in this zone. Variation of bending stiffness along specimen length generates shear stress concentrations in adhesive layer between CFRP and GFRP halves. In the real specimen the CFRP and CFRP halves can slide freely on the distance foil, while in analyzed, simplified model both halves are linked with the foil. There were not applied contact elements between foil and composite halves, but instead of it, there was assumed low E- and Gmodulus. That is why one can observe a big shear

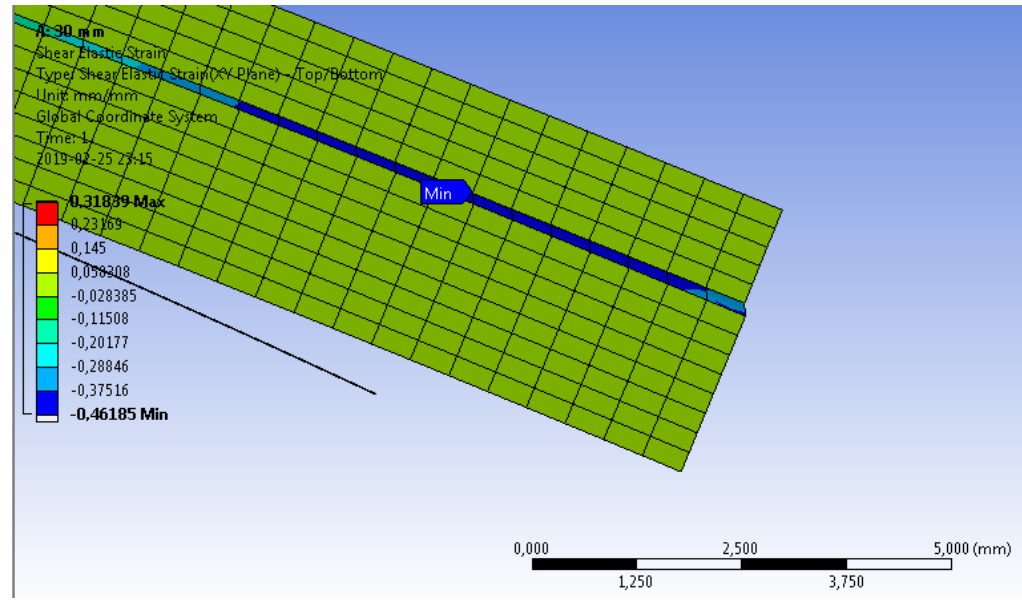

Fig. 11. Shear deformation the free end of the specimen deformation of this foil at the free-end of the specimen (Fig. 11). This simplification of distance foil model should not affect significantly the shear stresses in adhesive joint. Illustration of shear stress distribution along the specimen is shown in Fig. 12. As it arises from this Figure - the maximum values of shear stress is about $40 \mathrm{MPa}$ at the left tip of adhesive joint for all cases of adhesive length, and up to $14 \mathrm{MPa}$ more at the right tip (depending on the case of adhesive length. In the middle part of adhesive joint shear stress is very low (see Fig.13). 

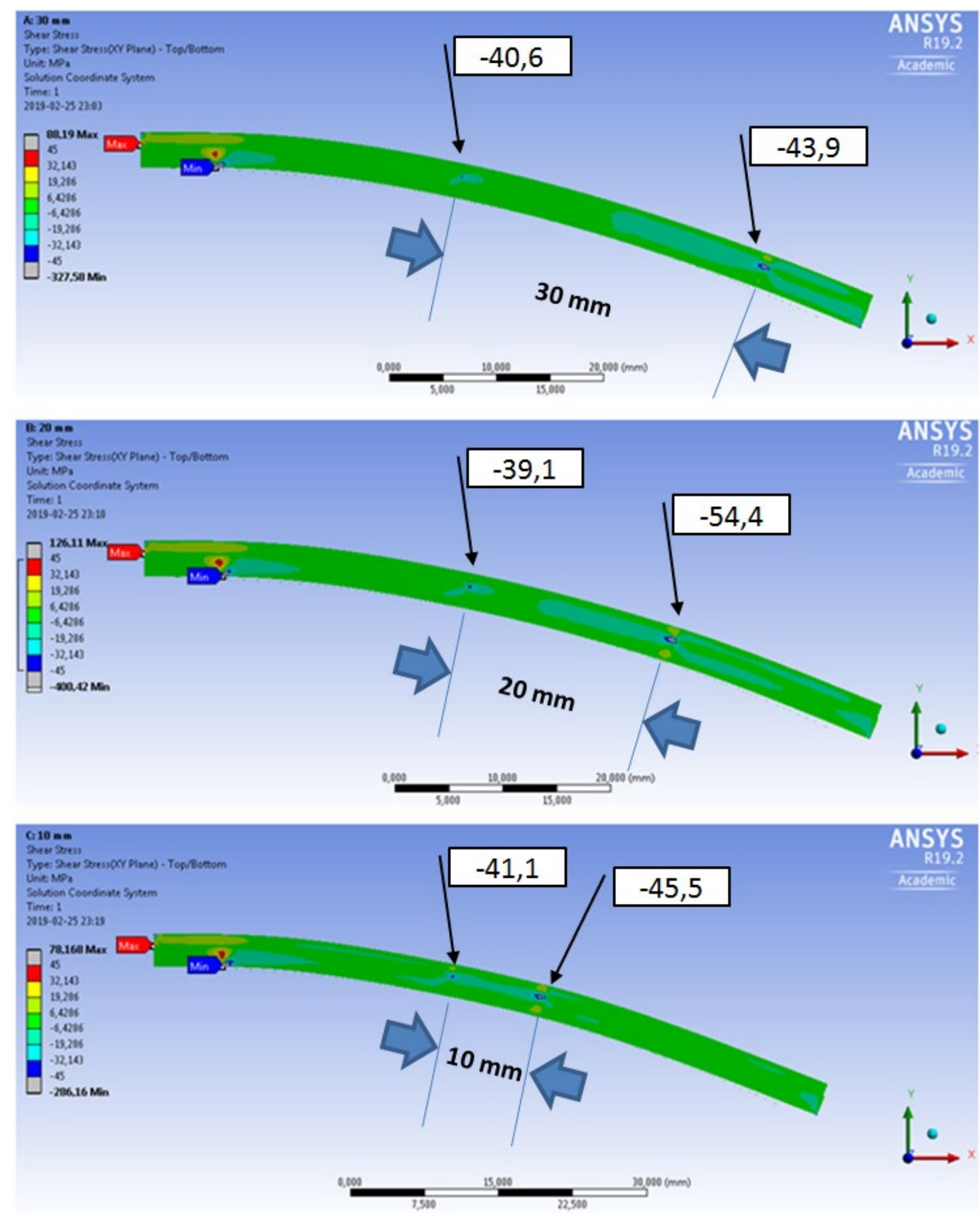

Fig. 12. Shear stress concentrations for different length of adhesive joint

Maximum values of the shear stress calculated from FEM-model exceed shear strength of epoxy-glue. From experimental part of work arises that the failure of adhesive joint did not appear during first load cycle, so it means that obtained values of shear stresses from FEMmodel are overestimated. The reason for it is such that instead of multi-layer-orthotropic model of material there was used isotropic material. 


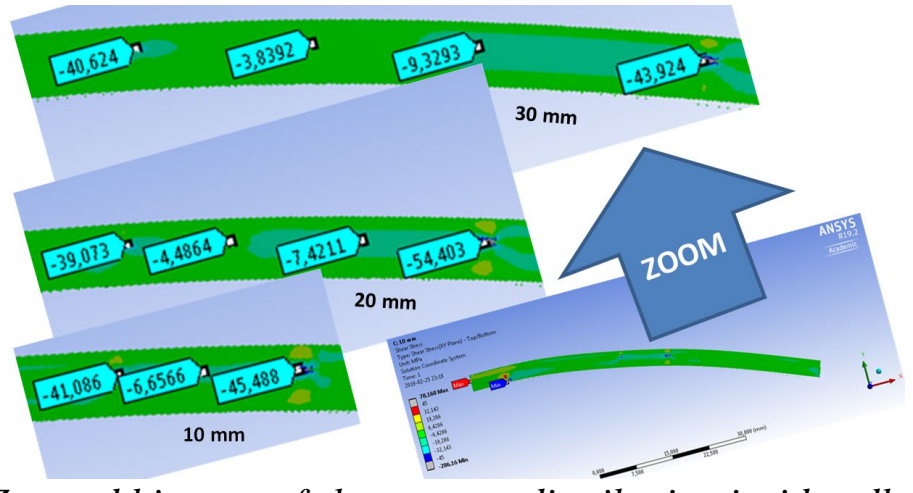

Fig. 13. Zoomed bitmaps of shear stress distribution inside adhesive joint

Another problem which is possible to evaluate basing on this FEM-model is the how much the state of specimen deformation using "bumper" as curvature template is similar to state of "pure bending". This question can be solved by analysis of distribution of normal stresses along bended specimen (Fig. 14). As it arises from the bitmaps - the stresses are uneven along the layer placed on the same radius of curvature, so such similarity is doubtful.
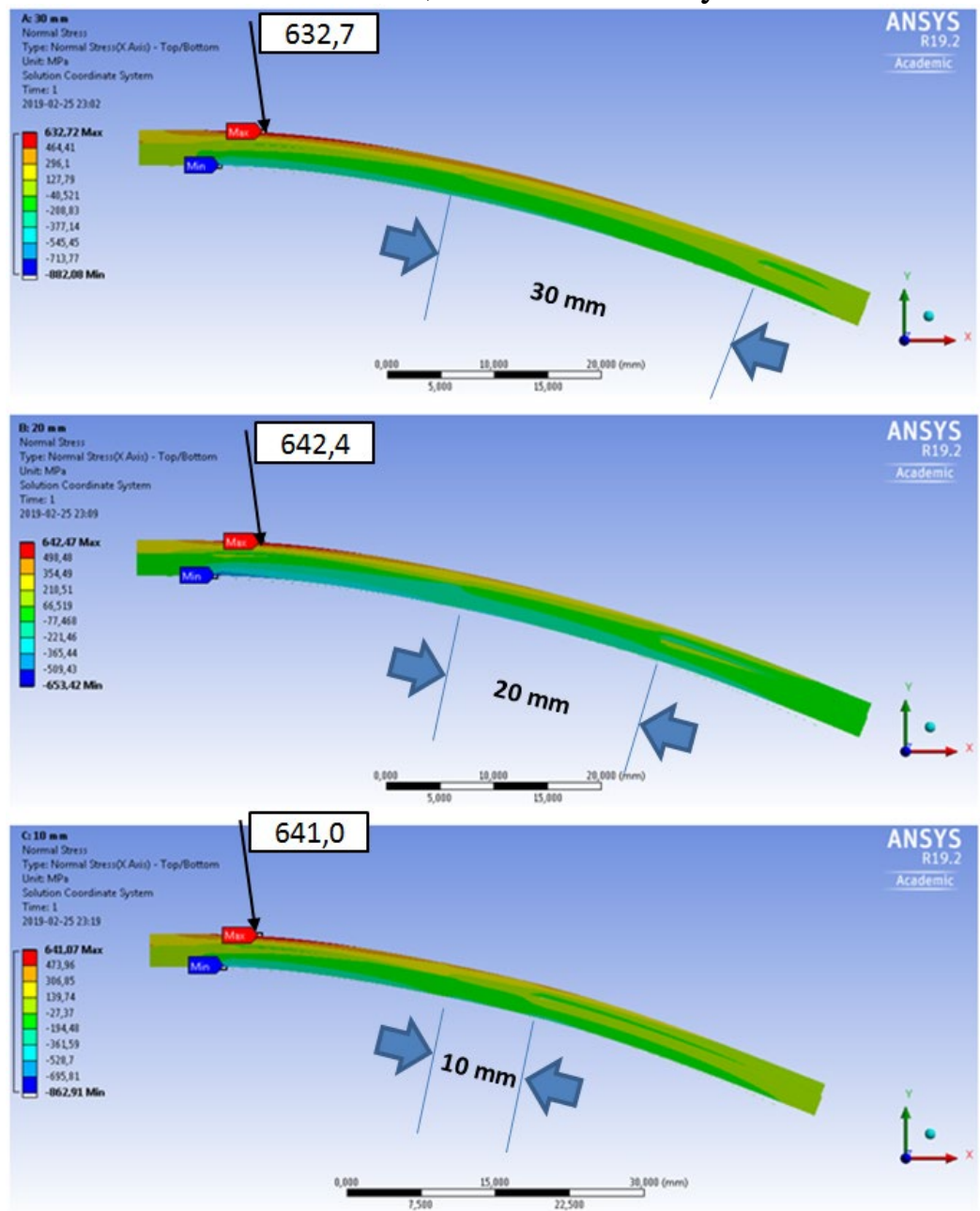

Fig. 14. Distribution of normal stress along the specimen

\section{Investigation of Epoxy Fracture Type by Microscope Usage}

To define how adhesive joint failed, the CFRP and GFRP specimen-halves were separated (see Fig. 15). 


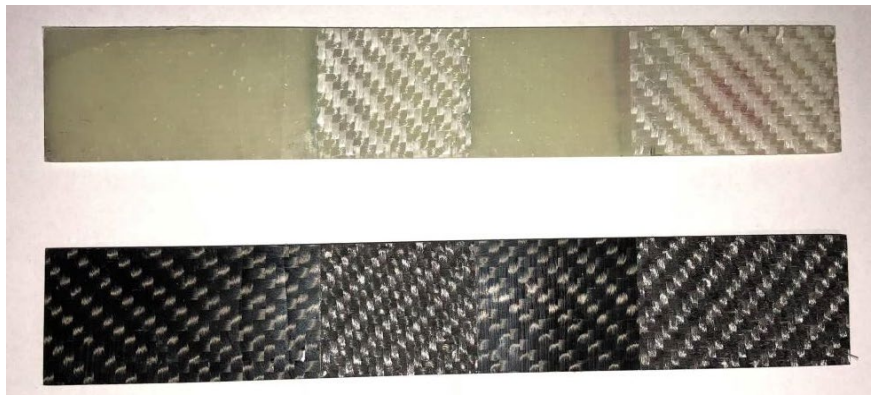

Fig. 15. CFRP and GFRP parts of the specimen (adhesive joint length $30 \mathrm{~mm}$ )

Photos of the CFRP and GFRP specimen-halves were taken using the digital microscope SMART SMP PRO. Photos were made of the inner side of specimen halves in non-glued and glued areas. This was done to understand in which way adhesive layer failed.

Several microscope photos were made and analyzed. The conclusion is that the fracture of adhesive joint between GFRP and CFRP halves of the specimen was cohesive, because the fragments of fractured epoxy layer are almost equally distributed on both halves of the specimen. Also are visible small de-cohesions inside GFRP material (see Fig. 16b), what proves good connection between GFRP and CFRP specimen-halves.

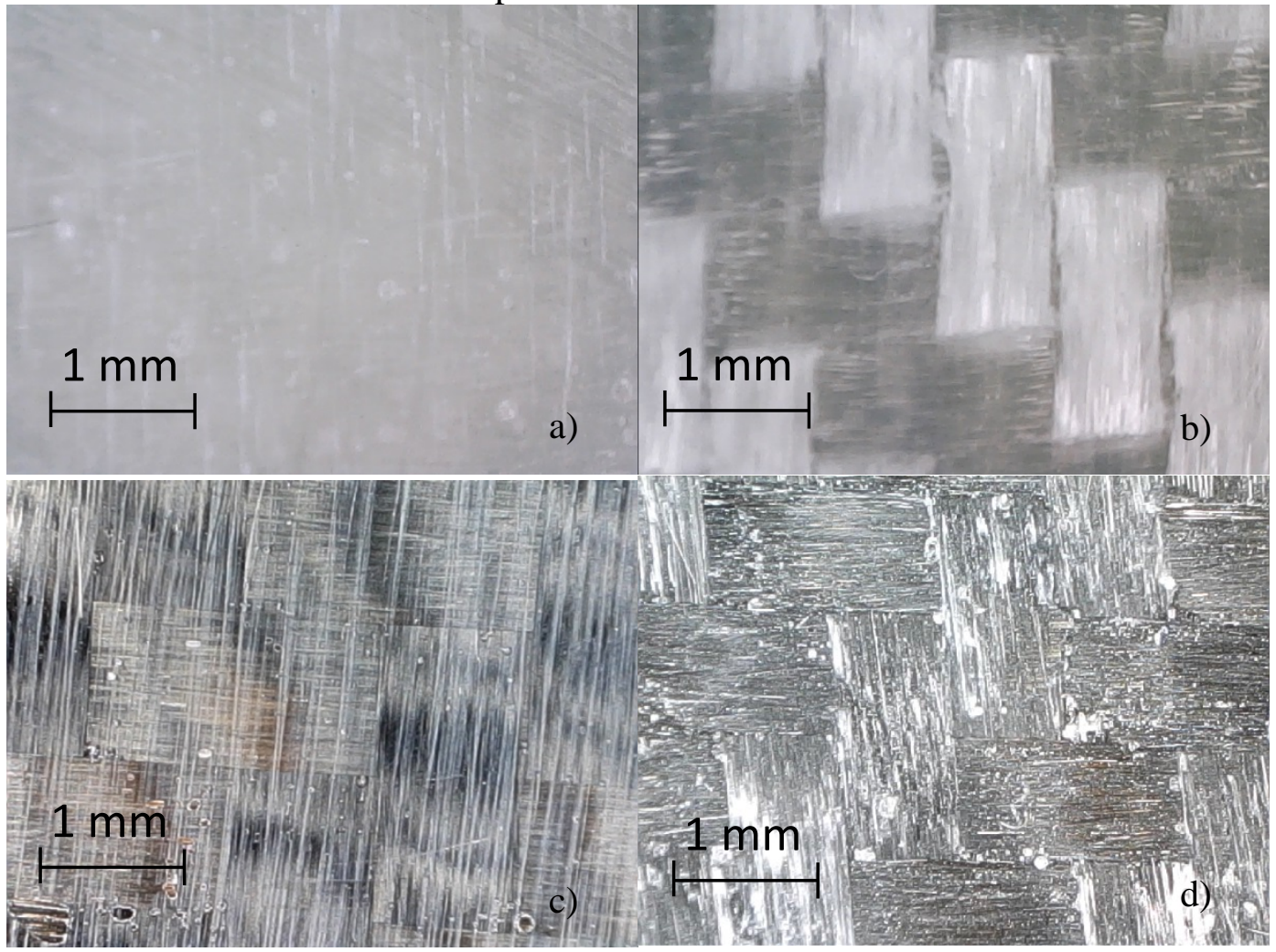

Fig. 16 Specimen areas under the microscope: a) GFRP surface non-glued; b) GFRP surface glued; c) CFRP surface non-glued; d) CFRP surface glued;

\section{Summary}

Low-cycle fatigue tests proved high performance of the adhesive joint between GFRP and CFRP halves of the specimens. Due to application of curvature templates with certain radius the specimen was subjected to bending. This bending induced shear loads inside adhesive joint between GFRP and CFRP parts. Three kinds of specimens with different length of adhesive joint 
were tested. Nonlinear dependence of number of load cycles versus failure propagation was observed.

After set of experiments and analysis it was found that the length of adhesive joint has crucial influence on fatigue life. Increasing the length from 10 to $30 \mathrm{~mm}$ one can observe the change of the number of cycles to failure from 20 to 763.

The stress value at the end of adhesive joint was calculated using simplified mathematical model (based on deflected specimen geometry analysis) and it was also simulated using FEM calculations of 2D models with different length of the adhesive joint. Also FEM-model was simplified, because there were used isotropic materials instead of multi-layer-orthotropic model of composites, and relatively poor mesh.

Both numerical and FEM models allowed to estimate shear stresses acting on adhesive layer, but accuracy of this estimation is too low. The improvement of FEM-model should be considered as the future action.

\section{References}

[1] Composite Structures, Design, Safety and Innovation, Book 2005 Edited by B.F. Backman, Elsevier Science

[2] Redux Bonding Technology, Hexcel corporation, Publication No. RGU 034c - Rev, July 2003

[3] K. Machalická, M. Eliášová, Adhesive joints in glass structures: effects of various materials in the connection, thickness of the adhesive layer, and ageing, International Journal of Adhesion and Adhesives, Volume 72, January 2017, pp 10-22.

https://doi.org/10.1016/j.ijadhadh.2016.09.007

[4] J. Marjanowski, J. Tomasiewicz, W. Frączek, The electric-powered motorglider AOS-71 -

The study of development. Aircraft Engineering and Aerospace Technology. 89. 10.1108/AEAT11-2016-0218. https://doi.org/10.1108/aeat-11-2016-0218

[5] Z. Brzoska, Wytrzymałość materiałów, Wyd. 4. Warszawa: Państwowe Wydawnictwo Naukowe,1983.

[6] IIT Kharagpur, Design of Adhesive Joints, Version $2 \mathrm{ME}$

[7] G. Krzesiński, T. Zagrajek, P. Marek, P. Borkowski, Metoda elementów skończonych w mechanice materiałów i konstrukcji: rozwiązywanie wybranych zagadnień za pomocą systemu ANSYS, Warszawa: Oficyna Wydawnicza Politechniki Warszawskiej, 2015. 